\title{
A corporação investigada: uma pesquisa quantitativa e qualitativa sobre a Polícia Militar do Estado do Rio de Janeiro
}

\section{Investigating the force: a quantitative and qualitative study of the Rio de Janeiro State Military Police Force}

\author{
Rodrigo Monteiro \\ Pesquisador do Núcleo de Pesquisa das Violências/Instituto de Medicina Social/ \\ Universidade do Estado do Rio de Janeiro \\ rodearmo@yahoo.com.br
}

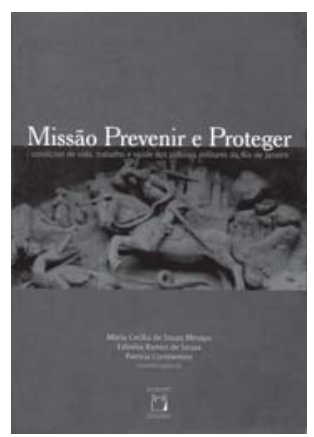

MINAYO, Maria Cecília de Souza; SOUZA, Edinilsa Ramos de; CONSTANTINO, Patrícia (Coord.). Missão prevenir e proteger: condições de vida, trabalho e saúde dos policiais militares do Rio de Janeiro. Rio de Janeiro: Editora Fiocruz, 2008. 328p.
$M$ issão prevenir e proteger é resultado de uma pesquisa coordenada por Cecília Minayo, Edinilsa Ramos de Souza e Patrícia Constantino e o produto final de vasto inquérito realizado entre 2005 e 2007. Traça minucioso perfil dos responsáveis pela manutenção da ordem em uma das principais cidades brasileiras e serve como referência para os estudiosos de segurança pública. Com a obra, as autoras completam o trabalho de investigar as polícias do Rio de Janeiro, uma vez que já analisaram a Polícia Civil (Minayo, Souza, 2003).

O livro é dividido em quatro partes: Contextualização, em que se expõe a metodologia de pesquisa, se analisa a formação social da Polícia Militar do Rio de Janeiro e é apresentado o perfil sociodemográfico, profissional e econômico; Condições de Trabalho dos Policiais Militares; Condições de Saúde e Risco profissional; e Condições e Qualidade de Vida.

As dificuldades enfrentadas pela equipe de pesquisadores e registradas no livro demonstram forte ausência de cultura de pesquisa quantitativa no Brasil, o que também tem tolhido o trabalho, por diferentes razões, de pesquisadores em favelas e condomínios de classe média e classe média alta das capitais brasileiras. Tais obstáculos têm reflexo na qualidade dos dados e exigem, das equipes de pesquisa, grandes esforços de estatísticos e demógrafos para dar conta das lacunas, além de imensa criatividade para convencer os 'donos dos pedaços' da importância da pesquisa.

Na pesquisa em questão, a dificuldade de acesso e autorização aponta para algo que é apresentado no percorrer do texto: a insipiente, frágil e resistente democratização de instituições brasileiras como a Polícia Militar do Estado do Rio de Janeiro. Já nas páginas iniciais somos informados de que os primeiros contatos com os comandantes dessa instituição se deram em 2000, porém os trabalhos de pesquisa só foram autorizados em 2005, após tramitar por gabinetes de diferentes comandantes, durante diferentes governos estaduais. 
Os percalços não terminaram na autorização oficial do alto comando da Polícia Militar. A entrega, a aceitação, o preenchimento e a devolução de questionários por parte dos entrevistados transformou-se em outra barreira a ser superada pela equipe de pesquisadores, como relatado no livro, o que reforça a necessidade de complementaridade na metodologia de coleta de dados.

Se os dados quantitativos apresentam limitações - ao mesmo tempo que expõem as contradições da corporação -, levantar as dúvidas e lançar mão de dados qualitativos para enriquecer, completar e robustecer a pesquisa são aspectos absolutamente legítimos, além de enriquecedores. De tal forma, a pesquisa da qual resultou o livro não se furtou em fazer grupos focais com os policiais militares de várias categorias hierárquicas, para tornar a investigação mais fértil.

A segunda parte do livro aponta para a história da corporação, e as autoras afirmam que a "ideia de empresa cidadã é inglória na Polícia Militar desde o seu início", no sentido de evidenciar a ausência de interlocução e diálogo com a sociedade civil, desde o início dos tempos da Polícia Militar no Rio de Janeiro. Um dos dados analisados é a formação de oficiais e não oficiais, que não é continuada depois do ingresso na corporação. Cerca de $72 \%$ dos oficiais e suboficiais, e cerca de $92 \%$ dos cabos e soldados relataram não frequentar cursos de formação. As autoras, contudo, ressaltam a importância recente de cursos com conteúdos de formação crítica e reflexiva, o aumento do número de horas dedicadas a discussões sobre segurança pública, o debate acerca de atuais pesquisas nacionais e internacionais sobre segurança pública, e a implementação de estágio prático supervisionado no interior dos batalhões, bem como a diminuição da carga horária de atividades como 'ordem unida'. Além desse fato, uma formação que não tem conexão com o que o policial militar vai exercer na sua carreira dentro da corporação é apontada na pesquisa, segundo a qual pouco mais de $45 \%$ dos não oficiais e pouco mais de $40 \%$ dos oficiais não receberam treinamentos para as atividades que propriamente exercem.

A relação com o trabalho e com a corporação é outro ponto de destaque. A necessidade de complementar o baixo salário com atividades conhecidas como bicos é fato preocupante e comum dentro da corporação, conforme os dados da pesquisa. O bico corresponde a uma parcela significativa dos ganhos mensais de policiais militares, e as autoras nos informam que quase $45 \%$ dos não oficiais recebem mais por esses trabalhos do que pela Polícia Militar. Entretanto, o inverso ocorre com os oficiais e suboficiais, pois $45 \%$ deles recebem mais pela corporação. A pesquisa revelou também que a principal ocupação fora da PM, para cabos e soldados, é a de segurança particular $(74,8 \%)$, tal como, aliás, a da maioria dos oficiais $(67,6 \%)$.

Ainda no que se refere às condições de trabalho, são reveladores os dados de insatisfação com o salário e do baixo reconhecimento da população, para oficiais e não oficiais de setores operacionais e administrativos. No mesmo quesito, a avaliação dos equipamentos operacionais ou administrativos utilizados pelos policiais militares, sejam eles oficiais ou não, é das piores. A maior nota (7) foi conferida por oficiais administrativos à "qualidade da arma de fogo", ao passo que a pior $(1,4)$ foi atribuída por não oficiais de setores operacionais às "máscaras de gás". 
O leitor pode sentir falta, no livro, de destaque para a questão da corrupção policial. Poucas e rápidas páginas abordam o tema, que não parece ter sido trabalhado em dados quantitativos. A questão é a principal causadora de mortes dos PMs, feridos com munições e armamentos supostamente vendidos por setores corruptos da própria corporação (Bandeira, 2007), além do que representa para a vida do cidadão comum, a cidade e o país.

Outro aspecto abordado brevemente é a truculência e o abuso de autoridade de PMs. Em síntese, a explicação das autoras é a de que a truculência e a corrupção são praticadas pela PM numa espécie de relação dialética da corporação com a sociedade: "a violência policial tem uma relação dialética com o que dela espera a sociedade autoritária e discriminadora".

De fato, vários autores apontam o viés autoritário e hierárquico da sociedade brasileira, especialmente o antropólogo Roberto DaMatta (1998), que também observa um certo descaso do brasileiro com as leis e as instituições da ordem. Para DaMatta, a sociedade brasileira não encontraria legitimidade nas leis, por não terem sido elas fruto de debates com a sociedade, mas sim impostas por suas elites. Mas seria essa a justificativa para que a polícia da cidade Rio de Janeiro fosse tão marcadamente vista como corrupta e truculenta, como mostram as pesquisas sobre vitimização (Zaluar et al., 2007). De fato, estudos apresentam a Polícia Militar como a mais mal vista pela população, quando comparada às Polícia Civil e Guarda Municipal, além de ser a mais desrespeitosa com mulheres negras e pobres na cidade. Além disso, nota-se uma certa nostalgia na população carioca, sobretudo entre os mais velhos, sobre a atuação dos antigos policiais chamados de Cosme e Damião, a indicar que os cidadãos detêm na memória boas atuações policiais, não marcadas por truculência ou corrupção. E mesmo recentemente, a imprensa tem registrado que membros das comunidades atingidas pelo programa das Unidades de Policia Pacificadoras (UPPs) estão avaliando positivamente suas impressões sobre a Polícia Militar.

A mídia é responsabilizada, para parte dos policiais entrevistados, pela imagem negativa da corporação junto a parcela significativa da sociedade carioca. Nesse aspecto as autoras dialogam com outros pesquisadores do tema e entendem haver um exagero da crítica feita pelos policiais à mídia. A pesquisa revelou ainda que, para os policiais militares do Rio de Janeiro, os governantes e o Estado também seriam responsáveis pela construção da imagem negativa da corporação. Ou seja, por parte dos policiais há pouca autocrítica de seus atos e dos de seus colegas de trabalho, e uma espécie de complacência com aqueles que agem mal moral e socialmente, a exemplo das práticas de corrupção e truculência.

A terceira parte do livro, igualmente rica em revelações e análises sociológicas, se debruça sobre a área de saúde e risco dos profissionais de segurança pública. Os constantes confrontos e 'guerras' travados contra traficantes revelam uma lógica oriunda do regime militar, qual seja, a ideologia do inimigo interno, segundo a qual o inimigo não seria o estrangeiro ou outra nação, mas sim indivíduos e grupos de cidadãos brasileiros instalados no país. Entretanto, a baixa procura de psicólogos e ajuda especializada revela um aspecto da cultura masculina que considera os homens imunes a 'doenças da mente' e até mesmo do corpo. As autoras informam, ainda, que tratamentos psicológicos são autorizados por superiores, o que pode expor a suposta fragilidade do policial diante do batalhão ou criar motivos para dispensa e licença médica, em batalhões com poucos efetivos. Não impressiona, 
portanto, que mais de $53 \%$ de oficiais e não oficiais tenham relatado que se sentem nervosos, tensos ou agitados, e que 7,9\% de oficiais e 5,6\% de não oficiais tenham declarado que já lhes ocorreu a ideia de dar cabo de sua vida. Nesse sentido, a dissertação de Leticia Freire da Rocha (2008) também presta enorme contribuição para o tema, ao buscar entender como os confrontos e a 'guerra' causa estresse pós-traumático em seus policiais.

Por outro lado, o policial militar tem uma profissão de risco, sobretudo quando o pano de fundo é a 'guerra' encadeada na região metropolitana do Rio de Janeiro - uma 'guerra' alimentada pela lógica de combate ao inimigo interno, como dissemos, e especialmente por políticas públicas de segurança baseadas no enfrentamento, que transforma policiais em vítimas. Tais políticas já demonstraram seu limite e sua pouca eficiência em todo o mundo, tanto para reduzir a violência urbana quanto na sua prevenção.

Outros dados da pesquisa relatada em Missão prevenir e proteger chamam atenção, entre eles o elevado número de policiais mortos em dias de folga (em 2004, morreram 2,8 vezes mais policiais em folga do que em serviço) e o fato de que soldados corresponderam a $55,3 \%$ dos policiais vitimados, entre 2004 e 2006, ou seja, os que mais morrem de causas violentas são aqueles de menor poder e prestígio na hierarquia da corporação. Mais: em 2004 a taxa de mortalidade por agressões, na Polícia Militar do Rio de Janeiro, chegou a 292/100 mil, ao passo que em 2000, na cidade, foi de 49,5/100 mil e no Brasil, de 26,7/100 mil.

Sobre a saúde física, última parte do livro, revela-se o Índice de Massa Corporal dos policiais. Entre oficiais, suboficiais e sargentos o índice foi $47,1 \%$; cabos e soldados apresentaram $48,3 \%$, indicando sobrepeso. Quanto ao peso, 23,4\% de oficiais, suboficiais e sargentos e $15,6 \%$ dos cabos e soldados estavam obesos. O estudo revelou que mais de $60 \%$ de policiais militares estão acima do peso ideal, o que nos remete a personagens como Sargento Garcia e Guarda Belo, que nunca conseguiam capturar seus delinquentes.

Embora a corporação tenha hospitais próprios, que também compõem o SUS, a pesquisa indica que os não oficiais gozam de pouco prestígio nesses espaços e se sentem mais bem atendidos em hospitais do SUS.

A quarta parte do livro apresenta interessantes contradições dos entrevistados, típicas de pesquisas quantitativas e qualitativas. Embora os policiais tenham assinalado a necessidade de complementar seu salário com bicos e expressem grande dose de insatisfação com a carreira, $64 \%$ de oficiais e $45 \%$ de não oficiais afirmaram que sua vida melhorou após o ingresso na PM, índices relativamente altos se comparados aos muitos relatos de dificuldades, tensões e questões críticas, como o baixo salário, o não reconhecimento social, as perdas de amigos e o medo de perder a vida. Com todos esses percalços, talvez seja ousado afirmar que "eles amam a profissão" (p.306); parece mais prudente entender que os policiais mantêm uma relação de amor e ódio com sua profissão. Não podemos deixar de ver, entretanto, que também há descaso, descompromisso, falta de sentimento de coletividade e de respeito à cidadania, ao mesmo tempo que uma série de graves e profundos problemas assolam a vida dessa corporação.

O livro é rico, profundo, revelador e deve ser objeto de interesse não só de estudiosos do tema como de gestores, desde que se mantenha a perspectiva de que é possível transformar a imagem e as práticas de uma corporação levando-a a um novo patamar e tornando-a 
permeável a projetos mais democráticos, participativos e permanentes (Muniz, Proença Jr., 2007).

As UPPs, implantadas pelo governo do estado do Rio de Janeiro desde 2008, têm conquistado a confiança de moradores, haja vista a quantidade de denúncias contra traficantes feitas por moradores dessas localidades. ${ }^{1}$ Porém não se pode abrir mão de reformas profundas e robustas, que redefinam o modelo policial brasileiro (Soares, 2006) e preparem essas corporações para atuar em sociedades democráticas, globais, tolerantes e em profundas transformações.

\section{NOTA}

1 "UPP recebe cem denúncias sobre autores de ataque a micro-ônibus na Cidade de Deus". O Globo, 4 mar. 2010. Disponível em http://oglobo.globo.com/rio/mat/2010/03/04/upp-recebe-cem-denuncias-sobreautores-de-ataque-micro-onibus-na-cidade-de-deus-915994743.asp; acesso em 5 mar. 2010.

\section{REFERÊNCIAS}

BANDEIRA, Antônio Rangel.

A importância da Comissão Parlamentar Sobre Armas. Em La Mira. Observador Latino Americano de Armas de Fogo, Rio de Janeiro, ano 2, n.5. 2007.

DAMATTA, Roberto.

Carnavais, malandros e heróis. Rio de Janeiro: Rocco. 1998.

MINAYO, Maria Cecília de Souza; SOUZA, Edinilsa Ramos de (Org.).

Missão investigar: entre o ideal e a realidade de ser policial. Rio de Janeiro: Garamond. 2003.

MUNIZ, Jacqueline de Oliveira; PROENÇA JR., Domício.

Muita politicagem, pouca política os problemas da polícia são. Estudos Avançados, São Paulo, v.21, n.61, p. 159-172. 2007.
ROCHA, Leticia Freire da.

Identidade do policial militar e dinâmica cultural. Dissertação (Mestrado) - Instituto de Medicina Social, Universidade do Estado do Rio de Janeiro, Rio de Janeiro. 2008.

SOARES, Luiz Eduardo.

Segurança pública: presente e futuro. Estudos Avançados, São Paulo, v.20, n.56, p.91-106. 2006.

ZALUAR, Alba M. et al.

Relatório final da pesquisa domiciliar de vitimização da cidade do Rio de Janeiro 2005 2006. Relatório de pesquisa. 2007. 